\title{
The biogeographic history of ruminant faunas determines the phylogenetic structure of their assemblages at different scales
}

\author{
Juan L. Cantalapiedra, Manuel Hernández Fernández and Jorge Morales \\ J. L. Cantalapiedra (jlopezcant@gmail.com) and J. Morales, Depto de Paleobiología, Museo Nacional de Ciencias Naturales (CSIC), Pinar 25, \\ ES-28006 Madrid, Spain. - M. Hernández Fernández and JLC, Depto de Paleontología, Facultad de Ciencias Geológicas, Univ. Complutense \\ de Madrid, José Antonio Novais 2, ES-28040 Madrid, Spain. MHF also at: Depto de Cambio Medioambiental, Inst. de Geociencias (UCM, \\ CSIC), José Antonio Novais 2, ES-28040 Madrid, Spain.
}

\begin{abstract}
Phylogenetic community structure may help us understand how macroecological and macroevolutionary processes shape assemblages at large geographical scales. In this paper, we test hypotheses linking the formation of large-scale assemblages, evolutionary processes and macroecology. To provide new insight into ruminant biogeography and evolution, phylogenetic community structure metrics were calculated for faunal assemblages at four hierarchical levels. Phylogenetic relatedness indices (net relatedness index and nearest taxon index) were determined for 59 ruminant assemblages at the landscape scale and scale of their respective climate domains (continuous biome stretches). Species pools at the global and biogeographic realm levels were used to construct null observation models. Significantly, assemblages were selected if they were distributed across biogeographic realms and represented all the world's biomes. Non-random patterns were also tested for biogeographic realms within the global ruminant species pool. By examining ruminant assemblages at different scales we were able to observe that ruminant faunas show a distribution mainly limited within the boundaries of their biogeographic realms. However, the diversification of some clades was found to be restricted to extremely arid domains in the Sahara and Arabia. The random patterns featured by other extreme climate domains could reflect phylogenetically heterogeneous filling by less biome-restricted lineages outside Africa.
\end{abstract}

Past evolutionary events can be inferred from living faunas. At the global scale, the distribution of species across continents and environments is determined by palaeobiogeographic episodes (Pickford and Morales 1994, Moreno Bofarull et al. 2008, Qian and Ricklefs 2008) and diversification rates controlled by environmental tolerance (Waldron 2010, Cantalapiedra et al. 2011) along with past climate and tectonic events, which influence and spur the two former processes (Vrba 1993, Vrba et al. 1995, van Dam et al. 2006). All these factors modulate cladogenesis events, faunal turnover and extinctions over millions of years, and thus shape the phylogenies of modern groups (Nee et al. 1992, Mooers and Heard 1997). Thus, studies designed to examine phylogenetic community structure will help identify the ecological and evolutionary processes underlying assemblage formation. The questions addressed in such studies are whether species in a given area are phylogenetically more closely related to each other than would be expected by chance (phylogenetic clustering), less closely related than expected by chance (phylogenetic overdispersion or evenness) or whether they represent a random subset of the regional pool of species (Webb 2000, Webb et al. 2002).

Many of the macroevolutionary episodes giving rise to today's phylogenies (e.g. niche filling, radiation, dispersal, extinction) were caused by biogeographical events (Wiens and Donoghue 2004). This means that distance estimates within or across assemblages based on phylogenetic trees will provide information on such events (Cardillo 2011). Depending on the size of the area under study and the different geographical scales used to delimit the species source pool, non-random patterns may arise from different macroecological or macroevolutionary processes (Heard and Cox 2007, Kamilar and Guidi 2010, Cardillo 2011). For example, if only a given subclade of a group examined occurs in a given region, localities within this region will show phylogenetic clustering compared with the species pool at the global scale. However, when compared with the continental species pool, such localities may exhibit a random phylogenetic structure or reveal other processes taking place within the region (Kraft et al. 2007, Cardillo 2011).

The interpretation of trends in community assemblages (particularly for small local-scale communities) has been subject to debate, since very different processes can result in similar patterns. For instance, two different assembly processes can render phylogenetic overdispersion (Kraft et al. 2007, Vamosi et al. 2009). This occurs because, firstly, competitive exclusion limiting ecological similarity can determine that species in a given assemblage are less closely 
related than would be expected by chance. Secondly, a certain environment may be prone to habitat filtering for convergent traits, thus also rendering evenly dispersed patterns of relatedness. Bearing in mind these shortcomings, recent research efforts have examined niche dynamics as well as testing assumptions related to trait evolution, the behaviour of phylogenetic structure metrics and the use of different null models (Gotelli 2000, Kraft et al. 2007, Kembel 2009).

Although community phylogenetic structure has been extensively explored, most work has been conducted on plants and microorganisms in local-scale communities (Vamosi et al. 2009). The study of mammalian assemblages is still relatively new and has mainly focussed on island faunas (Cardillo et al. 2008, Cardillo and Meijaard 2010), African carnivores (Cardillo 2011) and primates (Kamilar and Guidi 2010), mostly showing a tropical and subtropical distribution.

The present study was designed to survey ruminant assemblages worldwide. Including nearly 200 species, ruminants show the widest ecomorphological diversity among ungulates. The Arabian oryx Oryx leucoryx, adapted to one of the most extreme deserts on Earth, or the muskox Ovibos moschatus, which inhabits the northernmost regions of North America, are good examples. Ruminants also show diversity in terms of body size and behaviour, ranging from the solitary, $0.8 \mathrm{~kg}$ lesser chevrotain Tragulus javanicus, a browser that inhabits the densest tropical forests of southeast Asia, to the gnu Connochaetes gnou or buffalo Syncerus caffer, whose herds occur across the great savannahs of east Africa. Ruminants are distributed world-wide (naturally occurring in most continents, except Antarctica) and are among the most diverse and habitat-sensitive groups of large mammals (Vrba 1999, Vrba and Schaller 2000, Cantalapiedra et al. 2011). Their ecological diversity and wide distribution range makes these mammals particularly suitable for studies designed to test hypotheses on the effects of palaeobiogeography and macroecology on the phylogenetic structure of assemblages across different geographic and ecological scales (global, biogeographic realms, climate domains and landscape).

1) Within-realm limited faunas: if assemblages within a biogeographic realm are mainly made up of species of a certain subclade, due to within-realm radiation these assemblages will tend to exhibit phylogenetic clustering compared with the species pool at the global scale. However, compared with the species pool at the realm level, they will show random structure, unless other mechanisms are operating within the realm. At a macroecological scale (biome or ecoregion), these mechanisms may include, for example, strong habitat selection (Kraft et al. 2007; see below) or ecological sorting of faunas (Cardillo 2011). Finally, assemblages harbouring one or more species of a basal, longbranched lineage, may show phylogenetic overdispersion (Heard and Cox 2007). To test such a prediction, we first assessed the phylogenetic structure of species pools for biogeographic realms. Next, we determined the phylogenetic structure of assemblages at the realm level, constructing null models separately for both the global and realm species pools. These predictions could also be applied to continents. Continents and realms are similar in scale but differ in the nature of their boundaries (Fig. 1). Whereas continents are physically delimited, realms are defined both geographically and ecologically. By comparing phylogenetic signals for localities with the signals observed for species pools at the global, continental and realm scales it may be determined whether radiation was geographically or ecologically limited.

2) Extreme environments: some authors (Ackerly 2003, Kraft et al. 2007) have reported that extreme environments may drive the selection of derived adaptations to severe conditions (habitat filtering). Indeed, we would expect local assemblages in such environments to show strong phylogenetic clustering if these adaptations are phylogenetically conserved (Kraft et al. 2007), even when compared to the species pool of the respective biogeographic realm or continent. However, the clustering of local assemblages may be the result of habitat filtering at the biome scale. Biomes represent bioclimatically similar regions characterized by their gross vegetation physiognomy (Crisp et al. 2009). According to several authors, biomes have played an

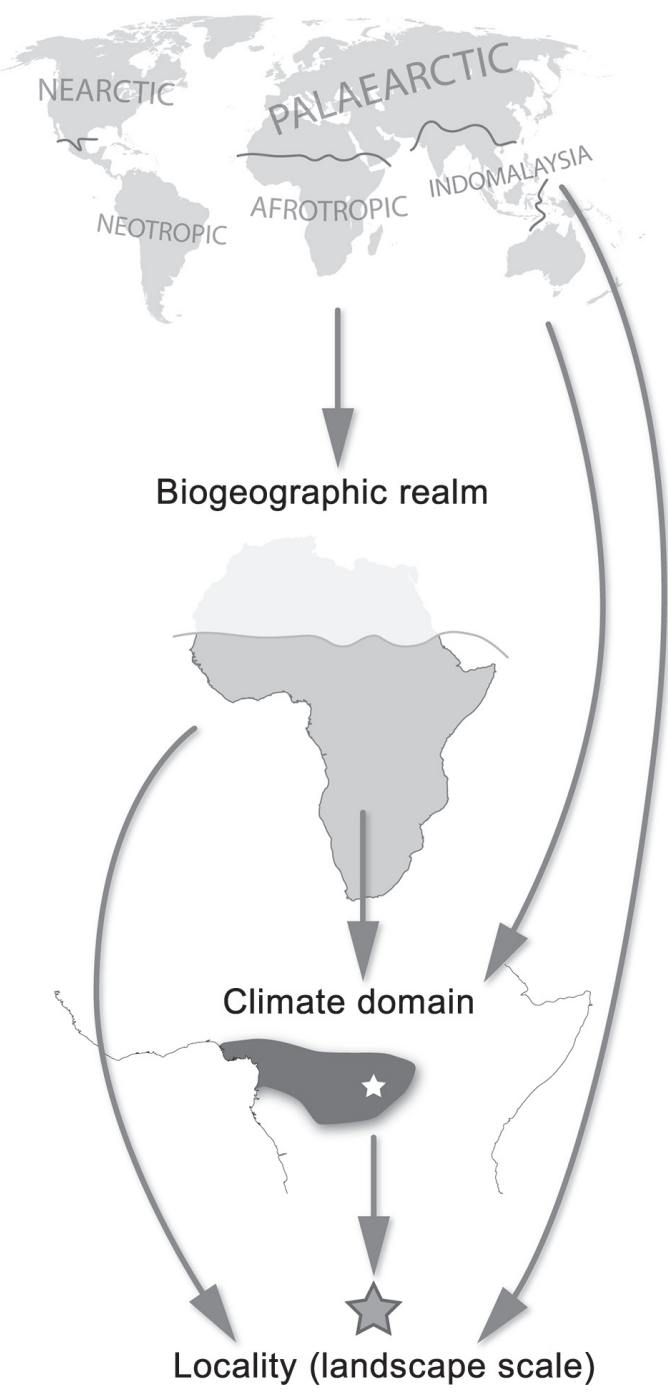

Figure 1. The image outlines the different levels considered in our analyses. Biogeographic realms were tested against the global species source pool; climate domains were tested against the global and respective biogeographic realm source pool; and localities (landscape scale) were tested against the global, respective biogeographic realm and climate domain source pools. 
important role in the evolution, biogeography, and macroecology of mammals (Vrba 1987, Hernández Fernández and Vrba 2005a, c, Moreno Bofarull et al. 2008, Cantalapiedra et al. 2011) allowing for cross-continental comparisons. However, biomes are not continuous so here we use climate domains (geographically continuous stretches of biomes, as proposed by Hernández Fernández (2001)) as bioclimatic units to test the prediction that extreme climate domains (deserts, cold steppes and tundras) and the localities within them, will show habitat filtering (Kraft et al. 2007) when compared to the species pool of the respective biogeographic realm. We would expect this phylogenetic signal to be particularly strong when such extreme environments select derived or phylogenetically conserved adaptations, showing phylogenetic clustering (Kraft et al. 2007). Since habitat filtering operates at the domain scale, we would also expect that local communities represent random subsets of the climate domain's species pool.

\section{Methods}

\section{Multiscale assemblages}

To test the hypotheses described above we examined the phylogenetic structure of ruminant assemblages at three different scales: landscape (referred to as locality for the sake of simplicity), climate domain and biogeographic realm (Fig. 1). To represent all the world's biomes (Supplementary material Appendix 1), we included as many climate domains as possible. Given our interest in the bioclimatic features of each climate domain, species restricted to the higher vegetation belts of mountain ranges were excluded since mountain ranges show bioclimatic and fauna particularities across biomes. We then selected one locality within each climate domain. Given our study was designed to assess macroevolutionary patterns shaping faunal assemblages, the smallest scale examined was landscape $\left(10000 \mathrm{~km}^{2}\right)$, sufficient to encompass both spatial variation in climate and all possible local habitats. To avoid bioclimatic variations arising from differences in topography (mainly mountain ranges), most localities were below $1000 \mathrm{~m}$ a.s.l. We assigned each locality to a climate domain following Allué Andrade (1990; Supplementary material Appendix 1). Localities and domains with less than two ruminant species or those on islands were not included in the analyses. In total, 59 localities and their respective climate domains were considered.

The five biogeographic realms considered were: Nearctic, Neotropic, Palaearctic, Afrotropic and Indomalaysian (Kreft and Jetz 2010; Fig. 1, Wallace 1876). The species pool corresponding to a biogeographic realm was taken as the complete list of species whose geographical distribution ranges fall within the realm. Lists of fauna for each locality, climate domain and biogeographic realm were obtained from the literature and online databases (Answell 1971, Corbet 1978, Eisenberg 1989, Corbet and Hill 1992, Redford and Eisenberg 1992, Grubb 1993, Kingdon 1997, MitchellJones et al. 1999, Eisenberg and Redford 2000, IUCN 2008). These lists include living species and those becoming extinct during the last two centuries. Species introduced by humans were omitted.

\section{Phylogenetic data}

Our study was based on a phylogenetic supertree that includes all 197 extant and recently extinct species of the suborder Ruminantia (Hernández Fernández and Vrba 2005b), following the nomenclature of Wilson and Reeder (1993). This supertree is a consensus of 124 trees published from 1970 to 2003 including morphological, ethological and molecular information. It was constructed using matrix representation with parsimony (MRP). Further, $80 \%$ of the nodes on the tree have been dated using a large compendium of molecular and fossil data and the remaining 20\% interpolated using a pure birth model (Hernández Fernández and Vrba 2005b). Accurate calibration of the tree is important to calculate relatedness indices based on phylogenetic distances (Pennington et al. 2006, Ives and Helmus 2010).

\section{Phylogenetic community structure metrics}

Phylogenetic structure metrics can be used as a measure of phylogenetic diversity. Some of these metrics have been used for absolute calculations of phylodiversity (e.g. total branch length on a chronogram), but more recently methods based on metrics aim to detect patterns of non-random community structure (Vamosi et al. 2009). By assessing phylogenetic structure metrics against a null model, we can determine whether the species that occur in a sample are more phylogenetically closely related than expected by chance (phylogenetic clustering), less closely related than expected by chance (phylogenetic overdispersion) or whether they represent a random subset of the regional pool of species (Webb 2000, Webb et al. 2002).

To assess the phylogenetic structure of assemblages (at the scales of locality, climate domain, and biogeographic realm) we determined the net relatedness index (NRI) and nearest taxon index (NTI), as standardized values, respectively, of mean pairwise distance (MPD) and mean nearest neighbour distance (MNND) by expectation from random draws (Webb et al. 2002). In short, NRI is a measure sensitive to phylogeny-wide patterns, whereas NTI is sensitive to patterns towards the tips of the tree. Both describe the difference between average phylogenetic distances in the observed assemblages and random simulations, standardized by the standard deviation of phylogenetic distances in the random simulations (Webb et al. 2008). An extensive review of the different community structure metrics available can be found in Vamosi et al. (2009).

Phylogenetic community analyses (NRI and NTI) were conducted on the species pools found at different geographic scales (Heard and Cox 2007, Kamilar and Guidi 2010, Cardillo 2011) (Fig. 1). We considered the four geographic scales: locality $\left(\sim 10000 \mathrm{~km}^{2}\right)$, climate domain, biogeographic realm, and global. Phylogenetic community indices were calculated for the first three scales, and null models for assemblage structure were constructed using all the geographic scales above each assemblage (Fig. 1). For example, the species pool for a biogeographic realm was only compared with the global pool (all species of ruminants). Species for climate domains were compared with 
those for their respective realm and the global species pool. Finally, species pools for localities were compared with those for their respective climate domain, biogeographic realm, and the global species pool (Fig. 1).

Since species restricted to high mountain ranges were excluded from the landscape and domain assemblages yet form part of the continent and realm species pool, we constructed a null model of randomly shuffling tip labels across the tips of the phylogeny. Thus, for each analysis, a 'regional tree' was obtained by pruning the ruminants tree.

NRI and NTI were implemented using the functions ses. mpd and ses.mntd, respectively, included in the R library picante (Kembel et al. 2009). The function prune.sample in the same package was used to generate the 'regional tree'. Two-tailed p-values were obtained by comparing the observed NTI and NRI values with those from 1000 random draws. Assemblages yielding a $\mathrm{p}<0.025$ were recorded as significantly clustered, while assemblages with a $\mathrm{p}>0.975$ were considered significantly dispersed (Cardillo 2011).

Finally, we repeated all the analyses involving the biogeographic realms using continents instead. That is to say, we calculated the phylogenetic signal for each continental assemblage, and used the continental species pool to construct the null models for the analyses of localities and climate domains. Four continents were considered: North America, South America, Eurasia and Africa. Nevertheless, results yielded by continents were similar to those generated by biogeographic realms and are thus only provided as Supplementary material Appendix 2. In addition, we focussed the discussion mainly on the results obtained for the species pool corresponding to the biogeographic realms.

To some extent, our results will vary according to future reinterpretations of phylogenetic relationships within the Ruminantia. Today, much of the debate on ruminant phylogenetics affects among-family interrelationships within the Pecora (all ruminants except tragulids) (Hassanin and Douzery 2003, Hernández Fernández and Vrba 2005b, Marcot 2007). Changes to these deep nodes will affect the net relatedness index (NRI), which describes broad phylogenetic patterns in community structure. Nevertheless, as splits among pecoran families took place at around the same period (Hassanin et al. 2012, late Oligocene to early Miocene; Hernández Fernández and Vrba 2005b, Meredith et al. 2011), this reorganization of the ruminant tree would not drastically modify phylogenetic distances among taxa, as the basis of phylogenetic structure metrics.

\section{Results}

Species assemblages for the Afrotropical, Palaearctic and Neotropical realms showed significant phylogenetic clustering according to both NRI and NTI (Table 1). The Indomalaysian realm showed NTI clustering (Table 1).

When species pools were compared by climate domains, 20 domains revealed phylogenetic clustering and one showed phylogenetic NRI overdispersion when their species assemblages were tested against the global species pool (Fig. 2A). According to NRI, three climate domains showed significant phylogenetic clustering (5\%; Sahara, Arabian dessert and savannahs) and one showed significant
Table 1. NRI and NTI indices calculated for assemblages in each biogeographic realm and continent. Asterisks denote significant phylogenetic structure when compared with 1000 null models constructed from the global species source pool.

\begin{tabular}{lccl}
\hline & Species richness & NRI & NTI \\
\hline Afrotropical & 79 & $5.87^{*}$ & $2.17^{*}$ \\
Palaearctic & 77 & $2.57^{*}$ & $4.27^{*}$ \\
Indomalayian & 46 & -0.43 & $3.01^{*}$ \\
Nearctic & 12 & 0.47 & 1.15 \\
Neotropical & 13 & $8.49^{*}$ & $4.48^{*}$ \\
Africa & 86 & $6.17^{*}$ & $1.72^{*}$ \\
Eurasia & 95 & -0.26 & $3.48^{*}$ \\
North America & 13 & 0.84 & 1.35 \\
South America & 13 & $8.72^{*}$ & $4.71^{*}$ \\
\hline
\end{tabular}

overdispersion (1.6\%; tropical rain forest of the Malay peninsula) when climate domains were analysed using the biogeographic realm as the species source pool (Fig. 2B). Two climate domains, the European Nemoral Deciduous Forests and the Central Asian Steppe returned NTI clustering in all the analyses, but their NRI indices were always consistent with random observations (Supplementary material Appendix 2).

When structure for the localities (landscape scale) was tested against the global species pool, 11 (18\%) localities showed significant phylogenetic clustering, 2 (3.3\%) showed phylogenetic dispersion and $47(79 \%)$ had a phylogenetic structure consistent with the random simulations conducted according to NRI (Fig. 3A). When we compared assemblage structures using biogeographic realm as the species source pool to construct null models, 58 localities $(98.3 \%)$ exhibited a phylogenetic structure consistent with the null model and only one (1.6\%) showed phylogenetic overdispersion (Fig. 3B). Most localities showed a phylogenetic structure consistent with the null model when climate domain was used as the source pool for constructing the null models (Fig. 3C).

We observed no strong relationship between assemblage sizes relative to those of the source pool and the p-values obtained (Supplementary material Appendix 3). The low coefficients of determination $\left(\mathrm{r}^{2}\right)$ obtained indicate no effect of relative assemblage size on the significance of clustering or overdispersion patterns.

\section{Discussion}

\section{Effect of biogeographic realm history on observations at smaller geographic scales}

Most of the assemblages that showed non-random phylogenetic structure patterns when compared to the global species pool, exhibited a random structure compared to the biogeographic realm species pool (Fig. $2 \mathrm{~B}$ and $3 \mathrm{~B}$ ). In addition, species assemblages for the biogeographic realms revealed high phylogenetic clustering (Table 1). These two observations suggest that assembly processes on the macroecological scale have shaped the phylogenetic structure of the realms, which in turn will affect phylogenetic relationships within the localities and climate domains that make up each realm. 

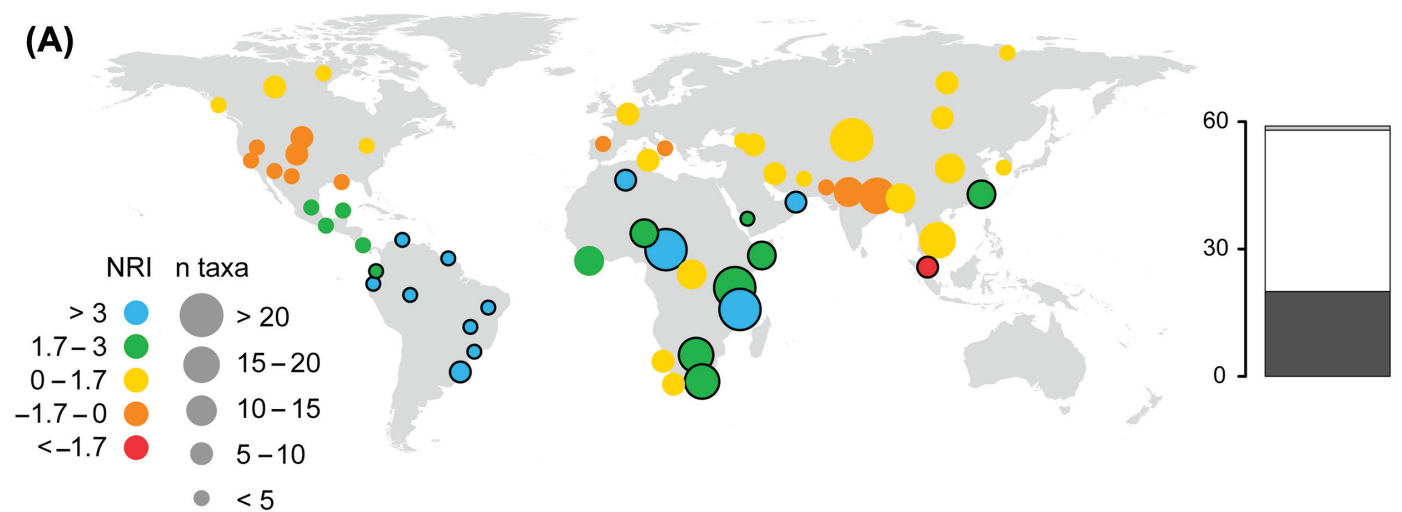

(B)
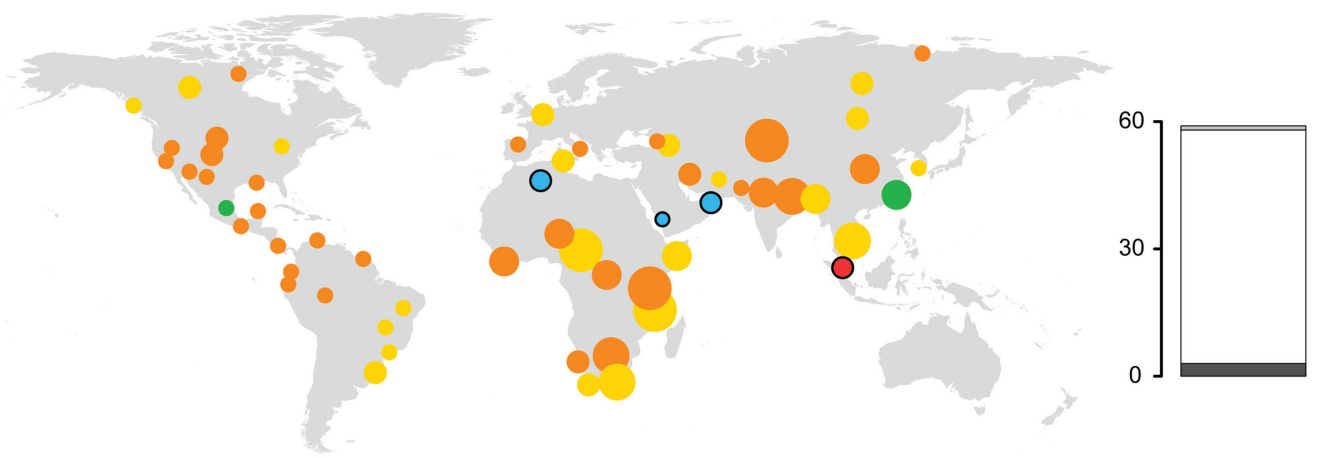

Figure 2. World maps showing climate domains and their corresponding NRI values (in colours) obtained against the global species pool (A) and biogeographic realm species pool (B). Circle sizes are proportional to species richness in each assemblage. Assemblages showing significant phylogenetic structure are outlined in black. To the right of each map, a plot shows the proportions of significantly clustered (dark grey, bottom), dispersed (light grey, top) or randomly distributed (white, middle) assemblages.

The Neotropics realm is a clear example. Out of 13 localities and 13 domains examined, species pools for 7 localities and 9 domains exhibited phylogenetic clustering (according to both NRI and NTI; Supplementary material Appendix 2) when compared to the global pool (Fig. $2 \mathrm{~A}$ and $3 \mathrm{~A}$ ). A further 4 climate domains in Central America yielded high NRI supported by marginally significant p-values ( 0.03 to 0.025; indicated in green in Fig. 2A). However, these assemblages did not show a phylogenetic pattern that differed significantly from the random expectations calculated for the Neotropics realm as the species source pool (Fig. 2B and $3 \mathrm{~B})$. This can be explained by the particular biogeographic history of neotropical ruminants. Thus, only 13 species of cervids have been identified in this region, all belonging to a single clade (Geist 1998, Hernández Fernández and Vrba 2005b) which arose as the result of explosive radiation of American generalist lineages of the Odocoileini tribe during the late Pliocene (Gentry 2000, Cantalapiedra et al. 2011). North American assemblages within the Neotropics returned a marginally significant NRI when compared to the global pool and continental pool, but showed nonrandom patterns when the biogeographic realm was taken as the source pool. This indicates that diversification of the New World's tropical deer was likely ecologically driven, and could be related to basal radiation of the group even before the appearance of the Isthmus of Panama (Duarte et al. 2008).

Similarly, we propose that the high clustering observed here for species assemblages of the Afrotropical realm, African localities, and climate domains can be related to the large-scale biogeographic history of this continent. Today, 82 out of 86 ruminant species living in Africa are bovids. Africa has been the cradle of several large cladogenetic events during the Neogene that gave rise to most of the existing Bovidae tribes (Bibi et al. 2009). During the Late Miocene and Pliocene, a period marked by a global increase in aridity and the expansion of open grasslands (Cerling et al. 1993, Hernández Fernández and Vrba 2006, Bobe et al. 2007), emerged a range of bovid tribes adapted to savannah-like environments. Subsequent radiations during the Plio-Pleistocene, coincident with massive cooling pulses, gave rise to some of the most successful bovid genera we see today (Vrba 1997, Hassanin and Douzery 1999, Bibi et al. 2009).

The ruminant assemblage of the Palaearctic realm, unlike the Eurasiatic assemblage, shows both NRI and NTI clustering. This indicates that the Palaearctic realm harbours more phylogenetically closely related taxa than Eurasia, suggesting a realm-limited distribution of ruminant faunas in this part of the Old World. The Palaearctic realm reveals much of the deer evolution process and shows a high diversity of caprins as a result of their radiation throughout the AlpineHimalayan belt from the Late Miocene onwards (Ropiquet and Hassanin 2005).

Overall, our results suggest the realm-limited establishment of ruminant faunas related to historical biogeography and climate aspects at this macroecological scale (Wiens and Donoghue 2004, Ricklefs 2007). This distribution would, in turn, affect the phylogenetic structure of smaller assemblages within the realms. This has long been acknowledged 

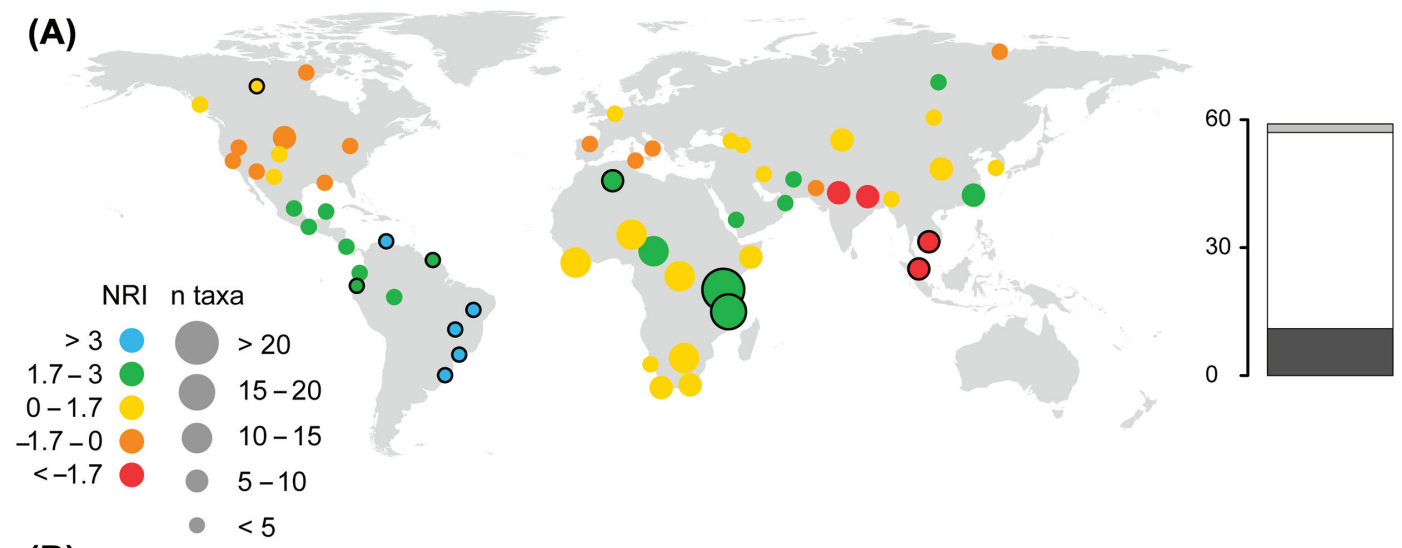

(B)
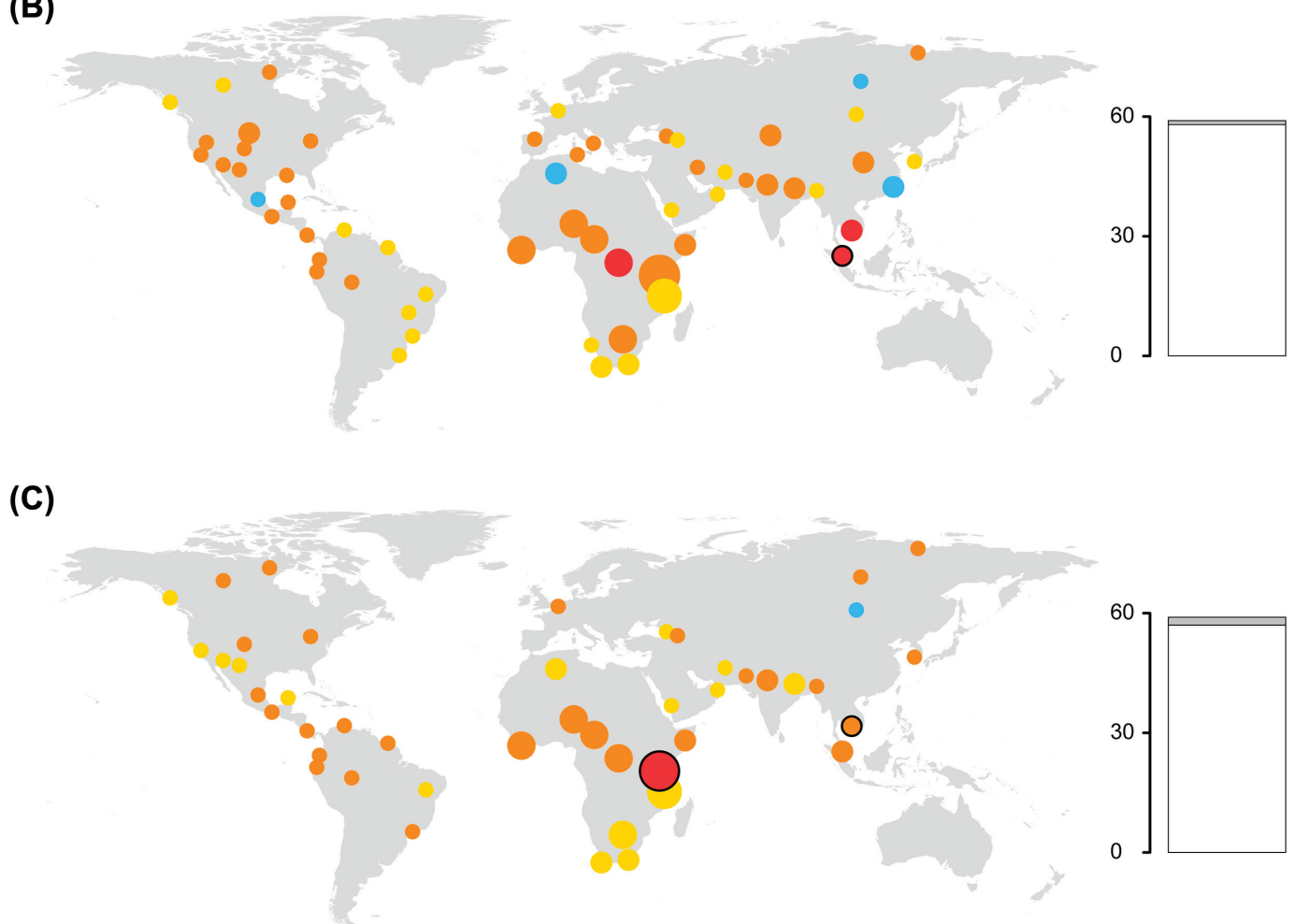

Figure 3. World maps showing localities and their corresponding NRI values (in colours) obtained against the global species pool (A), biogeographic realm species pool (B), and climate domain species pool (C). Only localities with fewer species than their respective climate domain are shown in (C). Circle sizes are proportional to species richness in each assemblage. Assemblages showing significant phylogenetic structure are outlined in black. To the right of each map, a plot shows the proportions of significantly clustered (dark grey, bottom), dispersed (light grey, top) or randomly distributed (white, middle) assemblages.

and several works have used biogeographic realms or continents as proxy indicators of historical factors (Ricklefs et al. 1981, Hawkins et al. 2003, Qian and Ricklefs 2008). With some exceptions, our results rule out the possibility of a domain-filling distribution of ruminant faunas, as reported for African carnivores (Cardillo 2011).

In general, phylogenetic indices for localities and assemblages yielded more non-random patterns when compared to the global pool than when compared to the biogeographic realm (Kamilar and Guidi 2010). Using simulations, Kraft and co-workers (2007) noted a loss of statistical power in phylogenetic structure metrics for small communities or those similar in size to the source pool, increasing the type II error (the metric may lead us to mistakenly reject a hypothesis of filtering or limiting similarity). Thus, we should expect less statistical power when comparing assemblages with the global source pool than the realm source pool, especially for very small assemblages. However, we detected a strong phylogenetic signal when very small assemblages were compared against the global pool (especially those in the Neotropics; Supplementary material Appendix 3, Fig. 1 and 2). This suggests that the strong biogeographic character of the patterns observed overcomes the potential pitfalls of the metrics.

\section{Overdispersed assemblages}

Not every assemblage yielded random patterns when compared to its respective realm. We found a few notable 
exceptions. Thus, Kuala Lumpur and its climate domain spanning the southern tropical rainforests of the Malay Peninsula and Phnom Phen, which lies in the tropical deciduous forests of Southeast Asia, showed phylogenetic overdispersion, even when compared to the species pool for the biogeographic realm (Fig. 2B and 3B). The phylogenetic signal of Kuala Lumpur probably reflects that of its climate domain (Malaccan Rain Forests). In contrast, Phnom Phen represents a particular case in which its faunas at the landscape scale are significantly overdispersed compared to the climate domain as the source pool. Both assemblages (those of the Malaccan Rain Forests and Phnom Phen) harbour tragulid species. Tragulids form a basal family that is sister to all other ruminants, and their local species richness plays a key role in the phylogenetic overdispersion of assemblages. Similar behaviour has been reported for relict assemblages of one or two species of a basal and depauperate clade in other mammalian groups (Heard and Cox 2007).

Interestingly, the locality showing the highest species diversity in our study (Voi, with 21 species) displayed phylogenetic clustering when compared to the global species pool, yet overdispersion was observed when compared to the faunal assemblage of its climate domain (east African savannahs; Fig. 3C). The same trend with marginal significance has been shown by other localities within other African savannah domains (Zinder and Gaberone; Supplementary material Appendix 2). Since savannahs are a transitional biome between tropical woodlands and deserts (Walter 1970, Allué Andrade 1990), we propose they could act as intermediate zones where climate fluctuations promote interchange and competitive sorting between faunas from different environments on a smaller scale, such as ecoregions (Cardillo 2011).

\section{Clustered assemblages}

Three climate domains showed NRI and NTI clustering within the global and realm faunas: the Sahara Desert, the Arabian Desert and the southwestern Arabian savannahs (Fig. 2 and Supplementary material Appendix 2). We propose that phylogenetic clustering in these climate domains could be attributed to two factors. The first of these factors is that these climate domains feature some of the most severe climate conditions for ruminants on Earth and require strong specialization of lineages for these to adapt and radiate into them (Hernández Fernández and Vrba 2005d, Cantalapiedra et al. 2011). Secondly, these are relatively new climate domains. The appearance of the Sahara Desert and other new arid ecosystems in the Western Palaearctic has been dated at around $2.7 \mathrm{Ma}$, coeval with the dramatic climate shift that spurred the onset of glacial-interglacial cycles in the Plio-Pleistocene (Leroy and Dupont 1994). Taken together, these data support the findings of prior work suggesting that the strong pattern of phylogenetic clustering obtained by habitat filtering of derived traits (in this case adaptations to extremely arid conditions) could be a distinguishing feature of novel and/or extreme environments (Kraft et al. 2007).

However, it is also true that assemblages in other subtropical deserts or extreme environments (e.g. cold deserts and tundra) did not exhibit phylogenetic clustering as predicted (Kraft et al. 2007), despite reports that these environments promote the biomic specialization of ruminant lineages (Cantalapiedra et al. 2011). We propose that ecological traits offering adaptive advantages in the Sahara and Arabian deserts and savannahs may be extremely phylogenetically conserved (as reflected by high NTI clustering), whereas traits related to the colonization of other extreme climate domains may be somewhat less conserved. This rationale is in line with the great geographical extension of Saharan-Arabian arid ecosystems, precluding colonization by many different groups except for the few able to adapt to these harsh environments (Hernández Fernández and Vrba 2005d). Alternatively, the colonization of these inhospitable regions not showing high phylogenetic clustering may be the result of the more complex and disperse biogeographic history of ruminants outside Africa (Cantalapiedra et al. 2011). While ruminant faunas in Africa are almost exclusively bovids, the biomes of Eurasia and North America are filled with more heterogeneous and, above all, more ecologically generalist faunas (Cantalapiedra et al. 2011). This could be the consequence of both temperate and cold climates, and the adaptation of ruminants to these environmental conditions.

Two climate domains showed NTI consistent with phylogenetic clustering when compared to the global and realm species pools (Supplementary material Appendix 2) yet their NRI values suggested a random phylogenetic structure. These domains were the European Nemoral Deciduous Forests and the Central Asian Steppe. Such clustered NTI values paired with NRI indices consistent with the null model reflect a relatively high proportion of sympatric congeners in disparate clades (Kamilar and Guidi 2010). This pattern could have been rendered by recent speciation events triggered by expansion-contraction and associated fragmentation in these climate domains during Pleistocene glacial-interglacial cycles (Adams et al. 1990, Prentice et al. 1993, Prentice and Jolly 2000).

\section{Final remarks}

Our results suggest that macroecological and macroevolutionary processes, such as the biogeographic history of ruminant clades, have shaped the phylogenetic structure of species assemblages at the scale of biogeographic realm. In turn, this structure will have its effects on the phylogenetic community structure shown by the localities and climate domains that make up these realms.

To date, phylogenetic community research on mammals has focused mainly on local-scale assemblages. This is the first study to explore the phylogenetic structure of mammalian communities at three different scales. Our findings, however, offer no more than a broad overview of global patterns of ruminant assemblages at very large geographic scales and we are still far from understanding the processes that shaped these assemblages or those of other mammals across all geographic levels and climate regimes. Future studies need to be based on multi-scale approaches to encompass the global diversity of environmental conditions.

Acknowledgements - The authors thank Blanca A. García Yelo for providing us with a preliminary version of the world distribution of biomes for Supplementary material Appendix 1, Jonathan Orr for 
proof-reading the manuscript, Anthony D. Barnosky and Susumu Tomiya for their observations and valuable feedback on the original manuscript and Ana Burton for editorial assistance. This study is a contribution by the PMMV Team (<http://pmmv.com.es $>$ ) and UCM 910607 Research Group on the Evolution of Cenozoic Mammals and Continental Palaeoenvironments funded by project grants CGL2011-25754, CGL2010-19116/BOS and CGL200601773/BTE. This study by the PMMV Team $(<\mathrm{http}: / / \mathrm{pmmv}$. com.es $>$ ) and UCM 910607 Research Group is a contribution to the project Evolution of Cenozoic Mammals and Continental Palaeoenvironments funded by grants CGL2011-25754, CGL201019116/BOS and CGL2006-01773/BTE.

\section{References}

Ackerly, D. D. 2003. Community assembly, niche conservatism, and adaptive evolution in changing environments. - Int. J. Plant Sci. 164: 165-184.

Adams, J. M. et al. 1990. Increases in terrestrial carbon storage from the Last Glacial Maximum to the present. - Nature 348: 711-714.

Allué Andrade, J. 1990. Atlas fitoclimático de España. - Monografías del Instituto Nacional de Investigaciones Agrarias 69: 1-223.

Answell, W. F. H. 1971. Order Artiodactyla. - In: Meester, J. and Setzer, H. W. (eds), The mammals of Africa: an identification manual. Smithsonian Inst. Press, pp. 1-84.

Bibi, F. et al. 2009. The fossil record and evolution of Bovidae: state of the field. - Palaeontol. Electron. 12: 1-11.

Bobe, R. et al. 2007. Patterns of abundance and diversity in late Cenozoic bovids from the Turkana and Hadar Basins, Kenya and Ethiopia. - In: Bobe, R. et al. (eds), Hominin environments in the east African Pliocene: an assessement of the faunal evidence. Springer, pp. 129-157.

Cantalapiedra, J. L. et al. 2011. Biomic specialization and speciation rates in ruminants (Cetartiodactyla, Mammalia): a test of the resource-use hypothesis at the global scale. - PLoS One 6: e28749.

Cardillo, M. 2011. Phylogenetic structure of mammal assemblages at large geographical scales: linking phylogenetic community ecology with macroecology. - Phil. Trans. R. Soc. B 366: 2545-2553.

Cardillo, M. and Meijaard, E. 2010. Phylogeny and co-occurrence of mammal species on southeast Asian islands. - Global Ecol. Biogeogr. 19: 465-474.

Cardillo, M. et al. 2008. Global patterns in the phylogenetic structure of island mammal assemblages. - Proc. R. Soc. B 275: 1549-1556.

Cerling, T. E. et al. 1993. Expansion of $\mathrm{C}_{4}$ ecosystems as indicator of global ecological change in the late Miocene. - Nature 361: 344-345.

Corbet, G. B. 1978. The mammals of the Palaearctic region: a taxonomic review. - Cornell Univ. Press.

Corbet, G. B. and Hill, J. E. 1992. The mammals of the Indomalayan Region: a systematic review. - Oxford Univ. Press.

Crisp, M. D. et al. 2009. Phylogenetic biome conservatism on a global scale. - Nature 458: 754-756.

Duarte, J. M. B. et al. 2008. The surprising evolutionary history of South American deer. - Mol. Phylogenet. Evol. 49: 17-22.

Eisenberg, H. J. F. 1989. Mammals of the Neotropics. Vol. 1: the northern Neotropics. - Univ. of Chicago Press.

Eisenberg, H. J. F. and Redford, K. 2000. Mammals of the Neotropics. Vol. 3: the central Neotropics. - Univ. of Chicago Press.

Geist, V. 1998. Strategies of deer evolution. - In: Geist, V. (ed.), Deer of the World: their evolution behaivour and ecology. Stackpole Books, pp. 1-18.
Gentry, A. W. 2000. The Ruminant radiation. - In: Vrba, E. S. and Schaller, G. B. (eds), Antelopes, deer, and relatives: fossil record, behavioral ecology, systematics and conservation. Yale Univ. Press, pp. 11-25.

Gotelli, N. J. 2000. Null model analysis of species co-occurrence patterns. - Ecology 81: 2606-2621.

Grubb, P. 1993. Order Artiodactyla. - In: Wilson, D. E. and Reeder, D. M. (eds), Mammal species of the World: a taxonomic and geographic reference. Smithsonian Inst. Press, pp. 377-414.

Hassanin, A. and Douzery, E. J. P. 1999. The tribal radiation of the family Bovidae (Artiodactyla) and the evolution of the mitochondrial cytochrome b gene. - Mol. Phylogenet. Evol. 13: 227-243.

Hassanin, A. and Douzery, E. J. 2003. Molecular and morphological phylogenies of ruminantia and the alternative position of the Moschidae. - Syst. Biol. 52: 206-228.

Hassanin, A. et al. 2012. Pattern and timing of diversification of Cetartiodactyla (Mammalia, Laurasiatheria), as revealed by a comprehensive analysis of mitochondrial genomes. - C. R. Biol. 335: 32-50.

Hawkins, B. A. et al. 2003. Energy, water, and broad-scale geographic patterns of species richness. - Ecology 84: 3105-3117.

Heard, S. B. and Cox, G. H. 2007. The shapes of phylogenetic trees of clades, faunas, and local assemblages: exploring spatial pattern in differential diversification. - Am. Nat. 169: E107-E118.

Hernández Fernández, M. 2001. Bioclimatic discriminant capacity of terrestrial mammal faunas. - Global Ecol. Biogeogr. 10: 189-204.

Hernández Fernández, M. and Vrba, E. S. 2005a. Body size, biomic specialization and range size of African large mammals. - J. Biogeogr. 32: 1243-1256.

Hernández Fernández, M. and Vrba, E. S. 2005b. A complete estimate of the phylogenetic relationships in Ruminantia: a dated species-level supertree of the extant ruminants. - Biol. Rev. 80: 269-302.

Hernández Fernández, M. and Vrba, E. S. 2005c. Macroevolutionary processes and biomic specialization: testing the resource-use hypothesis. - Evol. Ecol. 19: 199-219.

Hernández Fernández, M. and Vrba, E. S. 2005d. Rapoport effect and biomic specialization in African mammals: revisiting the climatic variability hypothesis. - J. Biogeogr. 32: 903-918.

Hernández Fernández, M. and Vrba, E. S. 2006. PlioPleistocene climatic change in the Turkana Basin (east Africa): evidence from large mammal faunas. - J. Hum. Evol. 50: 595-626.

IUCN 2008. Digital distributions maps of the mammals of te world. Version 1.0. - <www.iucnredlist.org/initiatives/ mammals/description/download_gis_data $>$.

Ives, A. R. and Helmus, M. R. 2010. Phylogenetic metrics of community similarity. - Am. Nat. 176: 128-142.

Kamilar, J. M. and Guidi, L. M. 2010. The phylogenetic structure of primate communities: variation within and across continents. - J. Biogeogr. 37: 801-813.

Kembel, S. W. 2009. Disentangling niche and neutral influences on community assembly: assessing the performance of community phylogenetic structure tests. - Ecol. Lett. 12: 949-960.

Kembel, S. W. et al. 2009. picante: R tools for integrating phylogenies and ecology. $-\mathrm{R}$ package ver. 0.7-1, <http:// picante.r-forge.r-project.org $>$.

Kingdon, J. 1997. The Kingdon field guide to African mammals. - Academic Press.

Kraft, N. J. B. et al. 2007. Trait evolution, community assembly, and the phylogenetic structure of ecological communities. - Am. Nat. 170: 271-283. 
Kreft, H. and Jetz, W. 2010. A framework for delineating biogeographical regions based on species distributions. - J. Biogeogr. 37: 2029-2053.

Leroy, S. and Dupont, L. 1994. Development of vegetation and continental aridity in northwestern Africa during the Late Pliocene: the pollen record of ODP Site 658. - Palaeogeogr. Palaeoclimatol. Palaeoecol. 109: 295-316.

Marcot, J. D. 2007. Molecular phylogeny of terrestrial Artiodactyls: conflicts and resolution. - In: Prothero, D. R. and Foss, S. E. (eds), The evolution of Artiodactyls. The John Hopkins Univ. Press, pp. 4-18.

Meredith, R. W. et al. 2011. Impacts of the Cretaceous terrestrial revolution and $\mathrm{KPg}$ extinction on mammal diversification. - Science 334: 524.

Mitchell-Jones, A. J. et al. 1999. The atlas of european mammals. - T. and A. D. Poyser.

Mooers, A. Ø. and Heard, S. B. 1997. Inferring evolutionary process from phylogenetic tree shape. - Quart. Rev. Biol. 72: 31-54.

Moreno Bofarull, A. et al. 2008. Influence of continental history on the ecological specialization and macroevolutionary processes in the mammalian assemblage of South America: differences between small and large mammals. - BMC Evol. Biol. 8: 1-18.

Nee, S. et al. 1992. Tempo and mode of evolution revealed from molecular phylogenies. - Proc. Natl Acad. Sci. USA 89: 8322-8326.

Pennington, R. T. et al. 2006. Insights into the historical construction of species-rich biomes from dated plant phylogenies, neutral ecological theory and phylogenetic community structure. - New Phytol. 172: 605-616.

Pickford, M. and Morales, J. 1994. Biostratigraphy and palaeobiogeography of east Africa and the Iberian Peninsula. - Palaeogeogr. Palaeoclimatol. Palaeoecol. 112: 297-322.

Prentice, I. C. and Jolly, D. 2000. Mid-Holocene and glacialmaximum vegetation geography of the northern continents and Africa. - J. Biogeogr. 27: 507-519.

Prentice, I. C. et al. 1993. modelling global vegetation patterns and terrestrial carbon storage at the Last Glacial Maximum. - Global Ecol. Biogeogr. Lett. 3: 67-76.

Qian, H. and Ricklefs, R. E. 2008. Global concordance in diversity patterns of vascular plants and terrestrial vertebrates. - Ecol. Lett. 11: 547-553.

Redford, K. and Eisenberg, H. J. F. 1992. Mammals of the Neotropics. Vol. 2: the southern Cone. - Univ. of Chicago Press.

Ricklefs, R. E. 2007. History and diversity: explorations at the intersection of ecology and evolution. - Am. Nat. 170: S56-S70.

Ricklefs, R. E. et al. 1981. A morphological analysis of the structure of communities of lizards in desert habitats. - Ecology 62: 1474-1483.

Supplementary material (Appendix ECOG-00236 at $<$ www.oikosoffice.lu.se/appendix $>$ ). Appendix 1-3.
Ropiquet, A. and Hassanin, A. 2005. Molecular phylogeny of caprines (Bovidae, Antilopinae): the question of their origin and diversification during the Miocene. - J. Zool. Syst. Evol. Res. 43: 49-60.

Vamosi, S. M. et al. 2009. Emerging patterns in the comparative analysis of phylogenetic community structure. - Mol. Ecol. 18: 572-592.

van Dam, J. et al. 2006. Long-period astronomical forcing of mammal turnover. - Nature 443: 687-691.

Vrba, E. S. 1987. Ecology in relation to speciation rates: some case histories of Miocene-Recent mammal clades. - Evol. Ecol. 1: 283-300.

Vrba, E. S. 1993. Turnover-pulses, the Red Queen, and related topics. - Am. J. Sci. 293A: 418-452.

Vrba, E. S. 1997. New fossil of Alcelaphini and Caprinae (Bovidae: Mammalia) from Awash, Ethiopia, and phylogenetic analysis of Alcelaphini. - Palaeontol. Afr. 34: 127-198.

Vrba, E. S. 1999. Habitat theory in relation to the evolution in African Neogene biota and hominids. - In: Bromage, T. G. and Schrenk, F. (eds), African biogeography, climate change and human evolution. Oxford Univ. Press, pp. 19-39.

Vrba, E. S. and Schaller, G. B. 2000. Introducction. - In: Vrba, E. S. and Schaller, G. B. (eds), Antelopes, deer, and relatives: fossil record, behavioral ecology, systematics and conservation. Yale Univ. Press, pp. 1-8.

Vrba, E. S. et al. 1995. Paleoclimate and evolution, with emphasis on human origins. - Yale Univ. Press.

Waldron, A. 2010. Lineages that cheat death: surviving the squeeze on range size. - Evolution 64: 2278-2292.

Wallace, A. R. 1876. The geographical distribution of animals: with a study of the relations of living and extinct faunas as elucidating the past changes of the Earth's surface. - Harper and Brothers.

Walter, H. 1970. Vegetation and clima. - Eugen Ulmer.

Webb, C. O. 2000. Exploring the phylogenetic structure of ecological communities: an example for rain forest trees. - Am. Nat. 156: 145-155.

Webb, C. O. et al. 2002. Phylogenies and community ecology. - Annu. Rev. Ecol. Evol. Syst. 33: 475-505.

Webb, C. O. et al. 2008. Phylocom: software for the analysis of phylogenetic community structure and trait evolution. - Bioinformatics 24: 2098-2100.

Wiens, J. J. and Donoghue, M. J. 2004. Historical biogeography, ecology and species richness. - Trends Ecol. Evol. 19: 639-644.

Wilson, D. E. and Reeder, D. M. 1993. Mammal species of the World: a taxonomic and geographic reference. - Smithsonian Inst. Press. 